\title{
The role of organic anion transporting polypeptides (OATPS/SLCOS) in the toxicity of different microcystin congeners in vitro: A comparison of primary human hepatocytes and OATP-transfected HEK293 cells
}

\author{
A. Fischer ${ }^{a, 1}$, S.J. Hoeger ${ }^{a, 1,2}$, K. Stemmer ${ }^{a, 1}$, D.J. Feurstein ${ }^{a}$, D. Knobeloch ${ }^{b}$, A. Nussler ${ }^{c}$, D.R. Dietrich ${ }^{a, *}$ \\ " Humen and Environmental Toxicology, University of Konstanz, Konstanz, Germany \\ Deportment of Generd, Visceral, and Transplant Surgery, Charite Campus Virchow, Betlin, Garmany \\ 'Technical University Munich, Department of Traumatology, Munich, Germany
}

Keywords:

Cyanobacteria

Microcystin

OATP

\begin{abstract}
A B S T R A C T
Ceflular uptake of microcystins (MCs), a family of cycic cyanobacterial heptapeptide toxins, occurs via specific organic anion transporting polypeptides (OATPs), where MCs inhibit serine/threonine-specific protein phosphatase (PP). Despite comparable PP-inhibitory capacity, MCs differ greatly in their acute toxicity, thus raising the question whether this discrepancy results from MC-specific toxikokinetic rather than toxicodynamic differences. OATP mediated uptake of MC congeners $M C L R,-R R,-L W$ and $-\mathrm{IF}$ was compared in primary human hepatocytes and HEK293 cells stably expressing recombinant human OATP1B1/SLCO1B1 and OATP1B3/SLCO1B3 in the presence/absence of OATP substrates taurocholate (TC) and bromosulfophthalein (BSP) and measuring PP inhibition and cytotoxicity. Control vector expressing HEK293 were resistant to MC cytotoxicity, while TC and BSP competition experiments reduced MC cytotoxiciry in HEK293-OATP transfectants, thus confirming the requirement of OATPS for trans-membrane transport. Despite comparable PP-inhibiting capabilities, MCLW and -LF elicited cytotoxic effects at lower equimolar concentrations than MCLR and MCRR, hence suggesting congener selective transport into HEK293-OATP transfectants and primary human hepatocytes. Ptimary human hepatocytes appeared one order of magnitude more sensitive to MC congeners than the corresponding HEK293 -OATP transfectants. Although the latter maybe due to a much lower level of PPS in primary human hepatocytes, the presence of OATPS other than 1B1 or 1B3 may have added to an increased uptake of MCs. In view of the high sensitivity of human hepatocytes and currently MCLR-only based risk calculations, the actual risk of human MC intoxication and ensuing liver damage could be underestimated in freshwater cyanobacterial blooms where MCLW and-LF predominate.
\end{abstract}

\section{Introduction}

Microcystins (MCs) are toxic metabolites produced by several cyanobacterial (blue green algae) species found in almost every environment worldwide. They are cyclic heptapeptides consisting of $>80$ structural congeners with a size between 909-1115 Da (Sivonen and Jones, 1999; 5poof, 2005; Zurawell et al., 2005; Humpage, 2008).

Their general structure is cyclo(-D-Ala ${ }^{1}-\mathrm{L}-\mathrm{X}^{2}-\mathrm{D}$-erythro-B-methyIAsp ${ }^{3}-\mathrm{L}-\mathrm{Z}^{4}-\mathrm{Adda}^{5}-\mathrm{D}-\mathrm{Gll}^{6}-\mathrm{N}$-methyldehydro-Ala ${ }^{7}$ ) in which Adda stands for the unique D-amino acid 3-amino-9-methoxy-2,6,8trimethyl-10-phenyldeca-4,6-dienoic acid and $X$ and $Z$ for variable I-amino acid residues (Botes et al., 1984, 1985; Rinehart et al., 1988, 1994). The MC congeners differ primarily in these two L-amino acids,

\footnotetext{
* Corresponding author. Fax: +497531883170 .

E-mat address: danieldienich@ini-konstanz.de (D.R. Dietrich)

1 These authors contributed equally.

${ }^{2}$ Current address: Harlan Laboratories, Itingen, Switzerland.
}

a trait also used for their nomenclature (Carmichael et al., 1988), and secondarily in slight modifications of the amino acids of the cyclic heptapeptide backbone, e.g. absence or additional methyl groups, etc

MCs are very potent inhibitors for serine/threonine-specific protein phosphatases (PPS), especially PP1 and PP2A, as well as PP3-PP6, whereas no inhibition of PP2B, PP2C and PP7 was observed (Mackintosh, 1993; Honkanen et al, 1994; Runnegar et al., 1995 Toivola et al., 1997; Hastie et al., 2005). MC-mediated inhibition of PPs results in hyperphosphorylation of numerous phosphate-regulated enzymes and subsequent deregulation of fundamental cellular processes, e.g. disruption of the cytoskeleton (Eriksson et al. 1990; Yoshizawa et al., 1990; Ohta et al, 1992; Wickstrom et al., 1995; Batista et al., 2003). The inhibitory capacity of single MC congeners on PP1 and PP2a in vitro is comparable, with $\mathrm{IC}_{50}$ values in the sub-and lower nanomolar range (Robillot and Hennion, 2004; Hoeger et al. 2007: Monks et al., 2007), suggesting a highly conserved molecular mode of action. Surprisingly, the $\mathrm{LD}_{50}$ values (mice, i.p.) for various $\mathrm{MC}$ congeners differ distinctly from one another, as summarized in 
Sivonen and Jones (1999). However, the overt discrepancy between similar in vitro $\mathrm{PP}$ inhibition (in situ toxicodynamics) and differing in vivo (i.p.) acute toxicity remains unresolved to date. This led to the initial hypothesis of this study that the toxicity of single MCs is primarily a result of their individual toxicokinetics (absorption and distribution) and not due to differences in toxicodynamics (PP-inhibition).

Indeed, as a result of their structure and amino acid composition, MCs are rather hydrophilic and spatially large molecules. Hence, they apparently are incapable of crossing cell membranes via passive diffusion, but rather require active transport via specific transporters, as suggested by indirect experiments (Eriksson et al, 1990a; Rumnegar et al.. 1995a) employing substrates for and inhibitors of organic anion transporting polypeptides (OATPS). Fischer et al. (2005) demonstrated that human OATP1B1, OATP1B3, OATP1A2 and rat Oatp1b2 [human: OATPS/SLCOs; animals: Oatps/Slcos; (protein name/gene symbol) (Hagenbuch and Meier, 2004)] are capable of transporting $\left[{ }^{3} \mathrm{H}\right]$-dihydromicrocystin-LR. The active uptake of native non-labeled MCLR and other MC congeners via OATPS was confirmed by using cells stably expressing OATP1B1 and OATP1B3, respectively (Komatsu et al., 2007; Monks et al., 2007). Recently, Lu et al. (2008) demonstrated a strongly decreased MCLR-mediated hepatotoxicity in Oatp1b2-null mice suggesting this knock-out model as useful for interpreting the importance of this transporter's human orthologs OATP1BI and OATP1B3 in the distribution of MCs and their ensuing potential toxicity. Indeed, members of the multispecific OATP family can be detected in nearly all tissues of humans, rodents and other animals. They play an important role in the absorption, distribution and excretion of numerous xenobiotica (Hagenbuch and Meier, 2003; 2004). While the human MCs-transporting OATP1B1 and OATP1B3, are exclusively located at the sinusoidal (basolateral) membrane of hepatocytes, OATP1A2 is located in the membrane of liver and kidney cells, as well as the blood-brain barrier (Meier and Stieger, 2002; Hagenbuch and Meier, 2003; van Montfoort ef al., 2003; Hagenbuch and Meier, 2004; Mikkaichi et al., 2004).

Therefore, using HEK293 cells stably expressing liver-specific OATP1B1 and OATP1B3 and primary human hepatocytes, this study determined whether the toxicity of single MCS (MCLR (L-leucine, Larginine), MCRR (1-arginine, L-arginine), MCLW (L-leucine, L-tryptophan) and MCLF (L-leucine, L-phenylalanine)) is a result of their individual toxicokinetics. To determine the toxicodynamic characteristics ( $\mathrm{PP}$ inhibition) of the four $\mathrm{MC}$ congeners, colorimetric protein phosphatase inhibition assays with recombinant PP1 and PP2A and homogenates of OATP1B1 and -1B3 expressing HEK293 cells were employed. Okadaic acid (OA), known to inhibit serine/threoninespecific protein phosphatases with similar potency as MCs (Mackintosh, 1993; Honkanen et al., 1994; Toivola et al., 1997; Hastie et al., 2005), yet capable of transport independent trans-membrane diffusion, was employed as a toxicodynamic and -kinetic positive control.

\section{Material and methods}

Chemicals and reagents. All chemicals were of the highest analytical grade commercially available. Standards of MCLR, MCRR, MCLW and MClF were obtained from Alexis (Switzerland) and dissolved in $75 \%$ MeOH. The concentrations of the stock and the working solutions were confirmed photometrically using the molar absorption coefficient of MCLR and MCRR ( $39800 \mathrm{~mol} \mathrm{l}^{-1} \mathrm{~cm}^{-1}$ ) published by Harada et al. (1990). Although this is the molar absorption coefficient for MCLR/-RR dissolved in $100 \% \mathrm{MeOH}$, it turned out to be applicable for 75\% MeOH as well (Meriluotoet al. 2004; Meriluoto and Spoof, 2005) In the absence of published molar absorption coefficients for MCLW and MCLF, the molar absorption coefficient for MCLR and MCRR was applied. Additionally, concentrations were confirmed by HPLC-DAD analysis according to Lawton et al. (1994). Okadaic acid (OA) (Sigma, Germany) was dissolved in $100 \% \mathrm{H}_{2} \mathrm{O}$, diluted to the stock and working concentrations according to the manufacturer's specifications. All toxins were sterile filtrated using a $0.22 \mu \mathrm{m}$ filter (Millex-GV, sterile; Millipore, Ireland).

Cell systems. Human primary hepatocytes were isolated in agreement with the ethical review board and after the patients' written consent by a standard operating procedure and cultured as described previously (Nussler et al., 2009). All four donors were females. Donor 1: partial liver resection due to cholangiocarcinoma (CCC), born 1961; donor 2: partial liver resection due to liver metastasis of primary mamma carcinoma, born 1965; donor 3: partial liver resection due to liver metastasis of primary colorectal carcinoma, born 1962; and donor 4: partial liver resection due to liver metastasis of primary colorectal carcinoma, born 1934 .

Human embryonic kidney cells (HEK293) stably transfected with recombinant human organic anion transporting polypeptides 1B1 (HEK293-OATP1B1) and 1B3 (HEK293-OATP1B3), or control vector (HEK293-CV) were kindly provided by Prof. Dietrich Keppler (Division of Tumor Biochemistry, German Cancer Research Centre, Heidelberg, Germany). HEK293 cells were cultured in minimal essential medium (MEM) with Earle's Salts and L-Glutamine supplemented with $10 \%$ FBS, 100 units $/ \mathrm{ml}$ penicillin, $100 \mathrm{mg} / \mathrm{ml}$

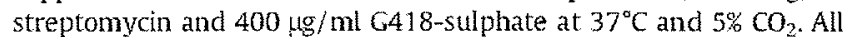
cell culture media and supplements were purchased from PAA Laboratories GmbH (Austria).

Toxin exposure. Passages 3-8 of transfected HEK293 cells were used for toxin exposure experiments. HEK293 cells were seeded in 96-well plates in MEM (supplemented as described above) at a density of $3 \times 10^{5}$ cells $/ \mathrm{ml}$ and $200 \mu \mathrm{l} /$ well $\left(6 \times 10^{4}\right.$ cells $/$ well). Prior to seeding, 96 -well plates were coated with poly-i-lysine $(5 \mathrm{mg} / \mathrm{ml})$. After $4-5 \mathrm{~h}$, the medium was decanted and cells incubated in $200 \mu \mathrm{MEM}$ (supplemented as described above, albeit with $1 \%$ FBS). Cells were incubated with serially diluted toxins (1:3); MCLR and -RR ranging from $5000 \mathrm{nM}$ to $2.29 \mathrm{nM}$, MCLW and -LF ranging from 200 to $0.09 \mathrm{nM}$ and $O A$ ranging from 93 to $1.15 \mathrm{nM}$, respectively.

For toxin exposure experiments, human primary hepatocytes of three different donors were used. Primary hepatocytes from donors 1 and 2 were employed to assess donor-specific differences in MCmediated cytotoxicity (see below). Cells were seeded in collagencoated 96-well plates (Price, 1975) at a density of $3 \times 10^{5} \mathrm{cells} / \mathrm{ml}$ and $200 \mu 1 /$ well $\left(6 \times 10^{4}\right.$ cells/well $)$. After arrival, the cells were incubated at $37^{\circ} \mathrm{C}$ and $5 \% \mathrm{CO}_{2}$ for $4-5 \mathrm{~h}$. Prior to exposure, the medium was decanted and replaced by $200 \mu \mathrm{RPMl} 1640$ containing 100 units $/ \mathrm{ml}$ penicillin and $100 \mathrm{mg} / \mathrm{ml}$ streptomycin. Cells were incubated with serially diluted toxins (1:3); MCLR and -RR ranging from 5000 to $2.29 \mathrm{nM}, \mathrm{MCLW},-\mathrm{LF}$ and $\mathrm{OA}$ ranging from 200 to $0.09 \mathrm{nM}$.

Co-incubation studies with bromosulfophthalein and taurocholate. $\quad \mathrm{Co}$ incubation studies of MCLR and taurocholate (TC) or bromosulfophthalein (BSP) in human primary hepatocytes of donor 3 and HEK293 transfectants were performed under identical conditions as described for single MC congener exposures (vide supra: toxin exposure) with the following modifications:

Primary human bepatocytes of donor 3 were seeded at a density of $2.25 \times 10^{6}$ cells $/ \mathrm{ml}$ and $200 \mu \mathrm{l} /$ well $\left(4.5 \times 10^{5}\right.$ cells $/$ well $)$ and exposed $4-5$ h subsequent to seeding. HEK 293 cells were exposed $4-5$ h subsequent to seeding.

Primary hepatocytes and HEK293 cells were exposed to concentrations of TC and BSP at $500 \mu \mathrm{M}$ and $166.7 \mu \mathrm{M}$ and $100 \mu \mathrm{M}$ and $33.3 \mu \mathrm{M}$, respectively, thus serving as OATP substrate controls.

Competition experiments in primary hepatocytes and HEK293 cells were carried out with $5 \mu \mathrm{M}$ MCLR in combination with 500,50 and $5 \mu \mathrm{M}$ TC or 100,50 and $5 \mu \mathrm{M}$ BSP. Based on the MCLR EC $\mathrm{C}_{50}$ values obtained in HEK293 transfectants, additional MCLR concentrations were used for TC and BSP competition experiments: 214 aM MCLR 
(EC 50 for HEK293-OATP1B1) for HEK293 cells transfected with OATP1B1 and 257.1 nM (EC 50 for HEK293-OATP1B3) for HEK293 cells transfected with $O A T P 1 B 3$. Since no $\mathrm{EC}_{50}$ could be determined for $C V$-transfected HEK293 cells, they were exposed to 214 and $257.1 \mathrm{nM}$ MCLR in combination with TC or BSP.

MTT reduction assay. Following $48 \mathrm{~h}$ exposure of HEK 293 cells or primary human hepatocytes to toxin, 20 l. MTT $(5 \mathrm{mg} / \mathrm{ml}$ ) solution was added to each well. Following incubation of the cells with the MTT solution for $1.5 \mathrm{~h}$, medium was carefully removed by pipetting. To re-dissolve MTT-formazan, $100 \mu \mathrm{ll}$ solubilization buffer $(95 \%(\mathrm{v} / \mathrm{v})$ isopropanol, $5 \%(\mathrm{v} / \mathrm{v})$ formic acid) was added to each well. After a minimum of 15 min careful shaking, absorption was determined at $550 \mathrm{~nm}$ in a microtiter plate reader (Tecan, microplate reader, infinite M200; Austria).

As positive control ( $0 \%$ survival), cells were incubated with $1 \%$ TWEEN ( 8 wells/96-well plate). Cells incubated with medium only (16 wells/96-well plate) were taken as negative control (100\% survival). The highest $\mathrm{MeOH}$ and water concentration in the assay was $<2 \%$ and used as solvent control ( 16 wells/96-well plate). No differences in viability, condition or growth rate could be identified between solvent and negative control (data not shown).

Colorimetric protein phosphatase inhibition (CPPIA) assay. The assay was carried out with MCLR, $-R R_{1}-\mathrm{LW},-\mathrm{LF}$ and okadaic acid $(\mathrm{OA})$ in concentrations diluted serially (1:3) from 600 to $0.03 \mathrm{nM}$ and 400 to $0.02 \mathrm{nM}$, respectively. MC congener-specific protein phosphatase inhibition in PP1 (rabbit skeletal muscle, recombinant (E. coli), New England Biolabs, USA) and PP2A (isolated from human red blood cells, Promega, USA) were determined as described by Heresztyn and Nicholson (2001) with the following minor modifications: both PP2A and PP1 were employed in stock concentrations of 500 units $/ \mathrm{ml}$ and 2,500 units $/ \mathrm{ml}$, respectively, which resulted in final assay concentrations of 1.5 units $/ \mathrm{ml}$ for PP2A and 3 units $/ \mathrm{ml}$ for PP1.P-nitrophenyl phosphate from Acros Organics, USA was used as substrate for the protein phosphatases. The absorption was measured at $405 \mathrm{~nm}$ in a microtiter plate reader (Tecan, microplate reader, infinite M200; Austria).

The assay was further modified when PPs of human primary hepatocytes homogenates (a mixture of donor 1 and 2 hepatocytes) or homogenates of HEK293-CV, -OATP1B1 and -OATP1B3 were used. After washing three times with PBS, cells were extracted in modified enzyme solution, containing $\mathrm{H}_{2} \mathrm{O}$ instead of BSA, for 10 min on ice while being re-suspended with a syringe and/or a pipette. Cell extract protein concentration was determined by the method of Bradford (Bradford, 1976) (Bio-Rad Protein Assay; Bio-Rad, Germany). Briefly, in a preliminary assay, homogenates of human primary hepatocytes HEK293-OATP1B1, HEK293-OATP1B3 and HEK293-CV were taken through a dilution series with enzyme solution in order to approach the highest protein phosphatase activity applicable which is restricted by the maximal optical density. For the final optimized inhibition assay, $3 \mu g / \mu$ of total protein of human primary hepatocytes and $0.4 \mathrm{\mu g} / \mu \mathrm{l}$ of total protein of each respective HEK293 transfectant were employed. Homogenates were incubated with the respective inhibitors for $30 \mathrm{~min}$ at $37^{\circ} \mathrm{C}$. Homogenates of the HEK 293 cells were incubated with all four MC congeners and $O A$ using the same concentration ranges as described above. Similarly, homogenates of human primary hepatocytes were incubated with MCLR and OA only and in concentrations diluted serially (1:3) from 600 to $2.47 \mathrm{nM}$ and 400 to $1.65 \mathrm{nM}$, respectively, due to limited availability of primary hepatocytes from donors 1 and 2 .

Immunoblot detection of PP1 and PP2A. Immunoblot detection was carried out as described previously (Feurstein et al., 2009) using $60 \mu g$ of total protein of primary hepatocytes from donor 4 , as well as with total protein from a mixture of donors 1 and 2 (see Fig. 1S). Monoclonal mouse antibodies anti-PP1\& (P7607; Sigma, Germany) and anti-PP2A (05-545; Millipore, Germany) were diluted 1:2000 and 1:500, respectively. The secondary HRP-labeled antibody rabbit antimouse (P0260; DakoCytomation, Germany) was applied in a dilution of 1:1000. GAPDH served as house-keeping protein control and was detected with a 1:200 dilution of rabbit polyclonal anti-GAPDH (sc25778, Santa Cruz Biotechnology Inc., USA). The secondary HRPlabeled antibody goat anti-rabbit ( $A 0545$; Sigma, Germany) was applied in a dilution of 1:160,000.

Immunofluorescence detection of OATPIB1 and OATP1B3. Primary human hepatocytes (mixture of donor 1 and 2) were seeded onto collagen-coated cover slips (Price, 1975) in 24-well-plates at a density of $0.5 \times 10^{6} \mathrm{cells} /$ well. HEK 293 cells were seeded on poly-L-lysin coated cover slips ( $5 \mathrm{mg}$ poly-L-lysin/ $\mathrm{ml}$ ) in 6-well-plates at the same density.

After three washes with PBS, cells were fixed by incubating with ice-cold Acetone/MeOH (1:1) for $5 \mathrm{~min}$. Following removal of the fixative, cells were dried on ice for another $5 \mathrm{~min}$ and subsequently stored at $-20^{\circ} \mathrm{C}$ until further treatment. Prior to incubation with the polyclonal primary antibodies, rabbit anti-OATP1B1 (König et aL. 2000a) and rabbit anti -OATP1B3 (König et al, 2000b), both kindly provided by Dietrich Keppler (Division of Tumor Biochemistry, German Cancer Research Centre, Heidelberg, Germany), for 1 h at room temperature cells were washed three times with PBS for 10 min each. These washing steps were repeated prior to and again after incubation with the TRITC-labeled secondary antibody goat antirabbit IgG (16778; Sigma, Germany) in the dark for another hour at room temperature. Finally, cells were washed once with $\mathrm{H}_{2} \mathrm{O}$, mounted with Fluorescent Mounting Medium (Dako, Germany) onto a slide and kept dark at $4^{\circ} \mathrm{C}$ until visualizing using a confocal laser microscope (LSM 510 META, Zeiss, Germany).

Statistics. Colorimetric PP-inhibition assays and cytotoxicity studies were carried out $\geq 3$ times in duplicates. Mean values and standard deviations were calculated based on the mean values of the replicates $(n \geq 3)$. For calculation of the respective $R^{2}, E C_{50}$ values and statistical analysis, GraphPad Prism 5 software was used. Briefly, the respective mean values were $\log$-transformed and normalized. The resulting curves were fitted by nonlinear regression. An F-test $(p<0.05)$ was employed for the comparison of the $\mathrm{EC}_{50}$ values, hill slopes and curves. Significant differences in cytotoxicity of individual microcystin-congener concentrations in comparison to concurrent controls were determined via one-way ANOVA followed by Dunnett's Multiple Comparison Test $(p<0.05)$.

Co-incubation studies were performed three to seven times in duplicates. The mean values of each duplicate yielded the values for calculation of the standard deviation ( $n \geq 3$ ). Significance of effect was determined via one-way ANOVA followed by Tukey's Multiple Comparison Test employed to assess significant differences between all groups (controls and exposures with/without competitor).

\section{Results}

Comparable toxicodynamics of different microcystin congeners

The $M C$ congener $I C_{50}$ values obtained with PP1A (Table 1; Fig. 1A) suggested a significant, albeit very small, difference in the mean phosphatase inhibiting capacity of the 4 different congeners, MCLR having highest activity followed by - RR, - LW and - LF, as shown by the non-overlapping $95 \%$ confidence intervals of the $\mathrm{IC}_{50}$ values of the individual congeners (Table 1). In contrast, the four different congeners did not demonstrate significantly different PP-inhibiting capabilities in recombinant PP2A (Table 1; Fig. 1B). However, all four $M C$ congeners inhibited the recombinant $\mathrm{PP} 1$ and $\mathrm{PP} 2 \mathrm{~A}$ halfmaximally between 0.9-1.9 nM, suggesting overall a comparable PP-inhibiting capability, thus toxicodynamic property, irrespective of the MC congener and PP employed. 
Similarly, no MC congener-dependent differences in PP-inhibition could be observed in the respective homogenates of HEK293-CV, HEK293-OATP1B1, and HEK293-OATP1B3 (Figs. 2A-D), thus corroborating the findings observed in the recombinant PPs. A comparable $\mathrm{PP}$-inhibition curve was obtained with the positive control, $O A$ (Fig. 2E). Of the total intracellular PP activity (100\%) present in the homogenates of HEK293 transfectants and primary human hepatocytes (a hepatocyte mixture of donor 1 and 2), MC congeners were capable of reducing PP activity to approx. $70 \%$ and to less than $90 \%$, respectively, thus suggesting a dramatically lower amount of ser/thr PPs in the primary human hepatocytes (Fig. 2F). A limited quantity of ser/thr PP in the human hepatocytes is also suggested by the fact that no dose-response was obtained, but rather already the smallest concentrations applied already reduced PP activity maximally (to $<90 \%$ of the total PP activity present).

Above interpretation is supported by PP1 and PP2A immunoblot analysis in homogenates of primary human hepatocytes and HEK293 transfectants. Whereas, HEK293 transfectants presented with comparable bands of PP1 and PP2A (supported also by densitometric analysis using the PP:GAPDH density ratio), only faint PP1 and marginal PP2A could be detected in the homogenates of the primary human hepatocytes of donor 4 (Fig. 3). Indeed, densitometric analyses suggested that quantities of PP1 and PP2A in the primary hepatocytes of donor 4 were only $35 \%$ and $8 \%$ of the values observed in the HEK293 transfectants (Table 15).

Microcystin congener-dependent cellular uptake in HEK293-transfectonts

The presence of OATP1B1 and OATP1B3 was confirmed immunocytochemically in plasma membranes of primary human hepatocytes (Donor 2; Figs. 4A and B) and HEK293 transfectants (Figs. 4C and D). However, the immunofluorescence signal appeared to be more intensive in the OATP-transfected HEK293 cells than in the primary human hepatocytes. No cross-reactivity of the 2 OATP-antibodies was observed (data not shown). As expected, no OATP-immunopositive signal was detected in HEK293 cells transfected with the control vector (Figs. $4 \mathrm{E}$ and $\mathrm{F}$ ).

Cells transfected with control vector showed no cytotoxicity irrespective of the MC congener or concentrations employed, whereas the cell-permeant positive control, $O A$, demonstrated the expected cytotoxicity (Fig. 5A). Indeed, nearly identical dose-response curves were obtained with $O A$ in all HEK293 transfectants $(A-C)$, although the $\mathrm{EC}_{50}$ values varied slightly with $9.5 \mathrm{nM}(8.2-11.1 \mathrm{nM}$; $\left.R^{2}=0.9605\right)$ for HEK293-CV, $10.5 \mathrm{nM}\left(9.3-11.7 \mathrm{nM} ; R^{2}=0.9569\right)$ for HEK293-OATP1B1 and $7.6 \mathrm{nM}\left(6.2-9.4 \mathrm{nM} ; R^{2}=0.9326\right)$ for HEK293-OATP1B3.

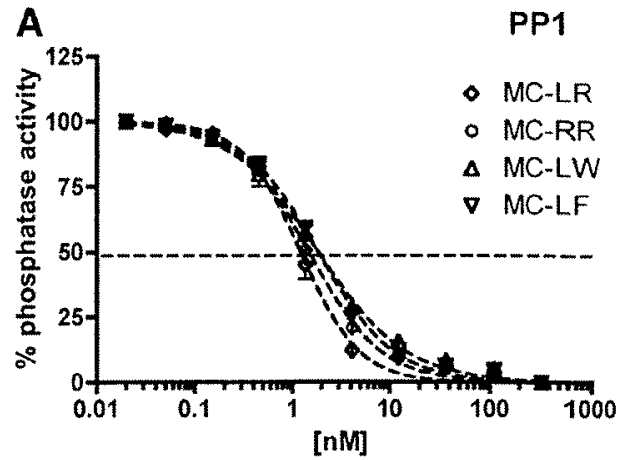

B

PP2A

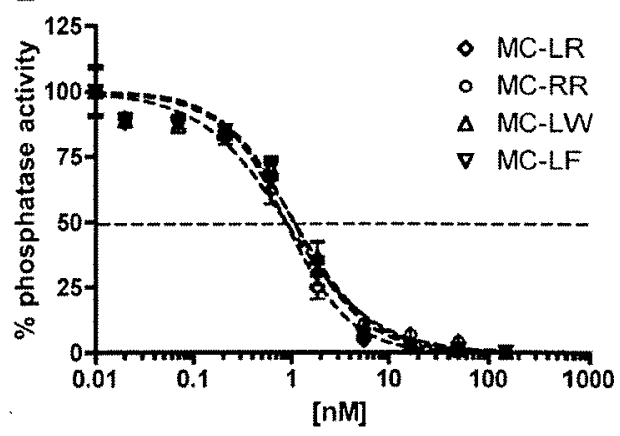

Fig. 1. Inhibition of the catalytic subunit of recombinant PPI (A) and PP2A (B) by MCLR $-\mathrm{RK},-L W$ and $-\mathrm{LF}$. Values represent mean \pm standard error of the mean of $\geq 3$ independent analyses.

In contrast. $\mathrm{MC}$ congener-dependent concentration-response curves were observed in OATP1B1-, as well as OATP1B3-transfected cells (Figs. $5 B$ and C). The EC 50 values for HEK293-OATP1B1 ranged from 10.4 nM for MCLW to beyond 5000 nM for MCRR. For HEK293OATP1B3, the $\mathrm{EC}_{50}$ values ranged from $3.7 \mathrm{nM}$ for MCLF to $1267 \mathrm{nM}$ for MCRR (Table 1). The $\mathrm{EC}_{50}$ values of the more hydrophobic MC congeners IW and LF were comparable among the transfectants, whereas the $\mathrm{EC}_{50}$ values of MCLR and -RR differed distinctly from each other. Although, MCLR gave a comparable dose-response curve in both HEK293-OATP-transfectants, HEK293-OATP1B1 cells appeared to be less susceptible to MCs than HEK293-OATP1B3. Indeed, MCLW and $-\mathrm{LF}$ are taken up much more rapidly or with higher affinity (up to 2 orders of magnitude) by HEK293-OATP1B1 and HEK293-OATP1B3 cells than MCLR or -RR. HEK293-OATP1B1 cells do not appear to transport MC-RR, whereas HEK293-OATP1B3 cells do transport MC-

Table 1

$\mathrm{IC}_{50} \mathrm{EC}_{50}$ values with $95 \%$ confidence intervals in brackets and LD50 (i.p. mouse) of the investigated MC congeners.

\begin{tabular}{|c|c|c|c|c|c|c|c|}
\hline & \multicolumn{2}{|l|}{$1 C_{s t s}(\mathrm{nM})$} & \multicolumn{4}{|l|}{$E C_{s B}(n M)$} & \multirow{2}{*}{$\begin{array}{l}L_{\text {so }}(\mathrm{nmol} / \mathrm{kg}) \\
\text { Mouse (i.p.) }\end{array}$} \\
\hline & PPI & $P P 2 A$ & $\begin{array}{l}\text { Prinary human } \\
\text { hepatocytes (donor } 1 \text { ) }\end{array}$ & $\begin{array}{l}\text { Primary human } \\
\text { hepatocytes (donor } 2 \text { ) }\end{array}$ & HEK293-OATP1B1 & НEK2S3-OATP1B3 & \\
\hline MCLR & $\begin{array}{l}1.2 \\
(1.1-1.4) \\
R^{2}=0.9876\end{array}$ & $\begin{array}{l}0.9 \\
(0.7-1.1) \\
R^{2}=0.9746\end{array}$ & $\begin{array}{l}3.4 \\
(2.9-4.1) \\
R^{2}=0.9647\end{array}$ & $\begin{array}{l}24.6 \\
(17.5-34.8) \\
R^{2}=0.9320\end{array}$ & $\begin{array}{l}214.0 \\
(161.5-283.5) \\
R^{2}=0.9285\end{array}$ & $\begin{array}{l}257.1 \\
(214.3-308.4) \\
R^{2}=0.9645\end{array}$ & $33-73 \div$ \\
\hline MCRR & $\begin{array}{l}1.5 \\
(1.3-1.6) \\
R^{2}=0.9891\end{array}$ & $\begin{array}{l}0.9 \\
(0.7-1.1) \\
R^{2}=0.9679\end{array}$ & $\begin{array}{l}167.2 \\
(125.8-222.2) \\
R^{2}=0.9372\end{array}$ & $\begin{array}{l}900.2 \\
(602.1-1346) \\
R^{2}=0.7725\end{array}$ & $>5000$ & $\begin{array}{l}1267 \\
(1089-1474) \\
R^{2}=0.9576\end{array}$ & $580-630: 2$ \\
\hline MCLW & $\begin{array}{l}1.9 \\
(1.7-2.5) \\
R^{2}=0.9876\end{array}$ & $\begin{array}{l}1.1 \\
(0.9-1.3) \\
R^{2}=0.9685\end{array}$ & $\begin{array}{l}0.5 \\
(0.4-0.5) \\
R^{2}=0.9779\end{array}$ & $\begin{array}{l}0.4 \\
(0.3-0.6) \\
R^{2}=0.9528\end{array}$ & $\begin{array}{l}10.4 \\
(8.3-13.0) \\
R^{2}=0.9536\end{array}$ & $\begin{array}{l}4.0 \\
(3.3-4.7) \\
R^{2}=0.9667\end{array}$ & nda \\
\hline MClF & $\begin{array}{l}1.8 \\
(1.7-2.0) \\
R^{2}=0.9939\end{array}$ & $\begin{array}{l}1.1 \\
(0.8-1.3) \\
R^{2}=0.9630\end{array}$ & $\begin{array}{l}0.5 \\
(0.4-0.6) \\
R^{2}=0.9839\end{array}$ & $\begin{array}{l}0.6 \\
(0.5-0.8) \\
R^{2}=0.9723\end{array}$ & $\begin{array}{l}11.1 \\
(9.0-13.5) \\
R^{2}=0.9420\end{array}$ & $\begin{array}{l}3.7 \\
(2.6-5.1) \\
R^{2}=0.8825\end{array}$ & nda \\
\hline
\end{tabular}

ndà no data available: $y$ I (Krishomanthy et al., 1986; Lovell et al. 1989: Stoner ef al. 1989): y2 (Watanabe et al., 1988; Sioner er al., 1989). 

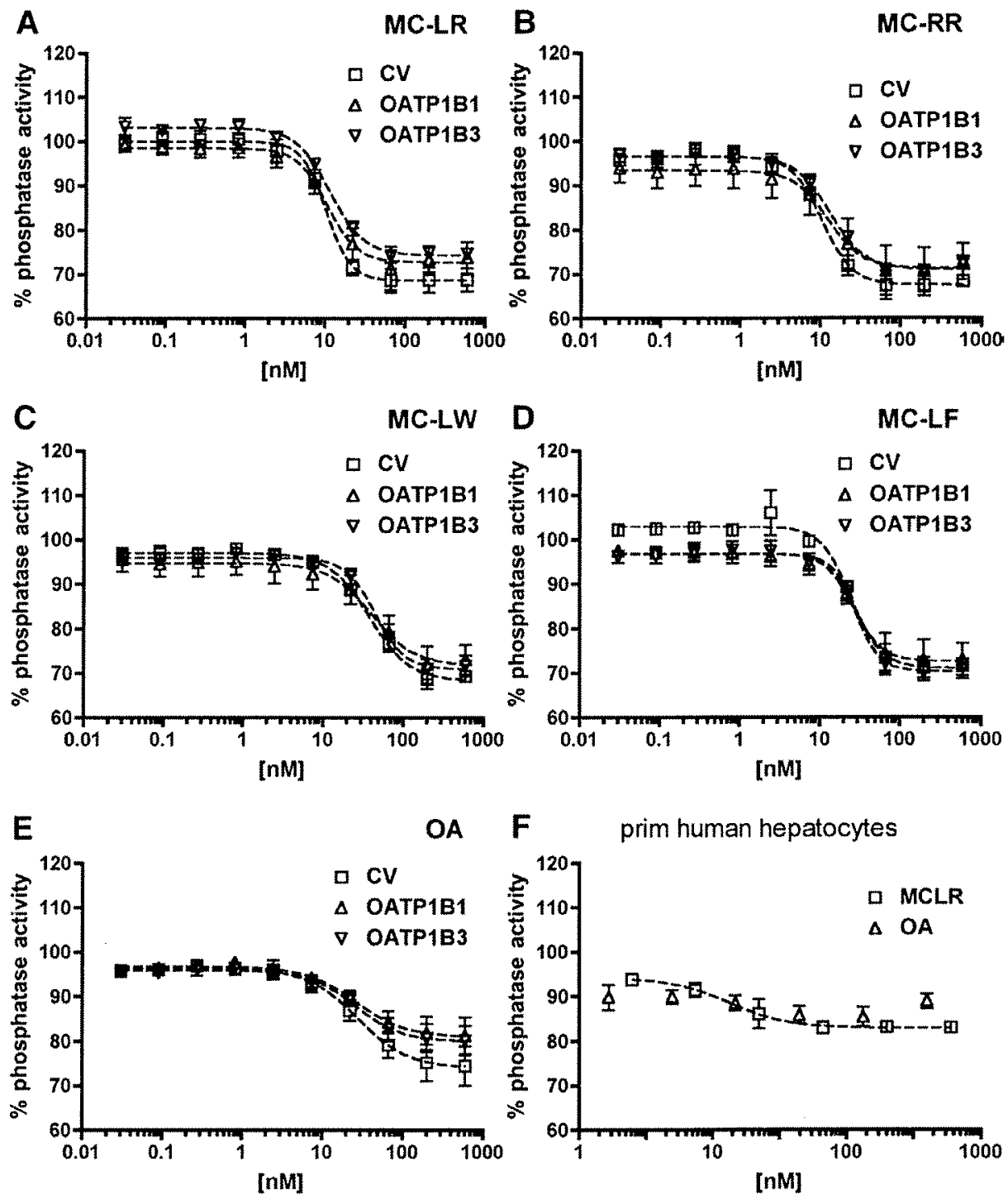

Fig. 2. Inhibition of intracellular ser/thr-specific PPS of HEK293-CV, -OATP1Bi and -OATP1B3 cell homogenates by (A) MCLR. (B) MCRR, (C) MCLW, (D) MCLF and (E) OA. (F) Inhibition of intracelluar ser/thr-specific PPs of primary human hepatocyte cell homogenates (mixture of cells from tonor 1 and 2 ) by MCL and OA. Values represent mean + standard error of the mean of $\geq 3$ independent replicate analyses.

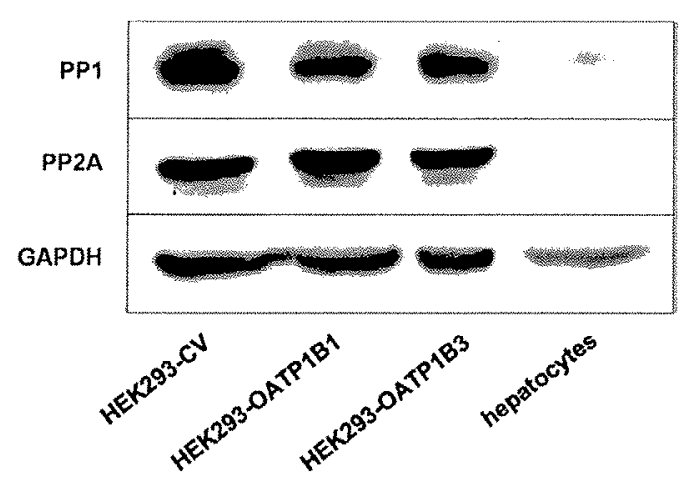

Fig. 3. Immunoblot detection of PPI, PP2A and GAPDH in primary human hepatocytes (donor 4), HEK293 cells transfected with a control vector, OATPIB1 and OATP1B3 Equal amounts of total protein $(60 \mathrm{mg} / \mathrm{lane}$ ) were applied. Molecular weights were estimated by comparison with marker proteins. Due to the low detection level of PP1 and $P P 2 A$ in primary human hepatocytes, the respective inages were overexposed.
$R R$ at approximately one order of magnitude less efficiently than MCLR and up to 4 orders of magnitude less efficiently than MCIW and $-\mathrm{LF}$.

While, MCLR had no effect on HEK293-CV-transfectants, high concentrations of TC $(500 \mu \mathrm{M})$ in the absence/presence of MCIR lead to significant buic limited cytotoxicity (Fig. 6A). In contrast, none of the HEK293-OATP transfectants were sensitive to TC cytotoxicity, whereas HEK293-OATP1B1 were susceptible to $100 \mu \mathrm{M}$ BSP and HEK293OATP1B3 were susceptible to 100 and $50 \mu \mathrm{M}$ BSP (Figs. 6C-F). A concentration of 33.3 UM BSP did not reduce viability in either OATP transfectants, albeit the HEK293-OATP1B3 cells appeared more sensitive toward BSP-mediated cytotoxicity than the OATP1B1 transfectants. MCLR competition experiments with the known OATP substrates TC and BSP demonstrated a reduction of MCLR cytotoxicity in both HEK293-OATP-transfectants. However, TC afforded protection from MCLR-mediated cytotoxicity at low concentrations of MCLR only. BSP, on the other hand, was protective in $5 \mu \mathrm{M}$ MCLR competition incubations at 100 and $50 \mu \mathrm{M}$ BSP in HEK293-OATP1B1 (Fig. 6D), while a $5 \mu \mathrm{M}$ BSP concentration was no longer protective. Similarly, BSP was protective in HEK293-OATP1B1 at lower MCLR 


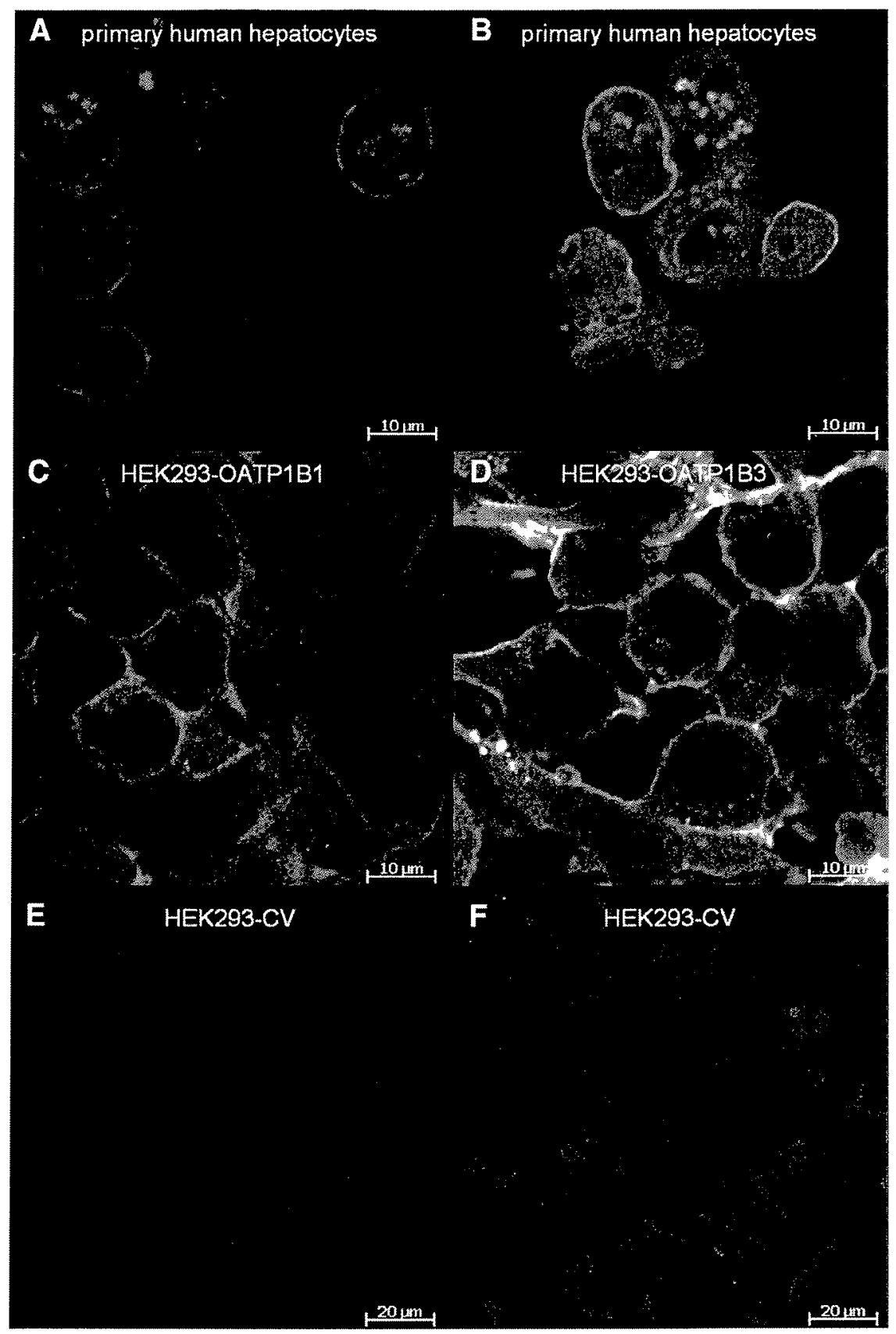

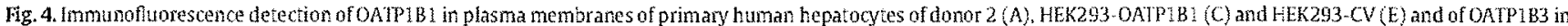
plasma memoranes of primary human hepatocytes (B), HEK293-OATP1B3 (D) and HEK293-CV (F). Note the absence of siainitg in HEK293-CV when stained with OATP1B1 and OATP1B3 antibody.

concentrations. In contrast, due to the high cytotoxicity of BSP in IIEK293-OATP] B3 cells, only the non-cytotoxic 5 UM BSP concentrations afforded protection from 257.1 nM MCLR-mediated cytotoxicity (Fig. 6F).

Microcystin congener-dependent cellular uptake in primary human hepatocytes

As observed in the HEK293-transfectants, MC congener-dependent cytotoxicity was observed in the primary hepatocytes of both donors (Fig. 7), whereby MCLW and -LF were the most, MCLR intermediate, and MCRR the least cytotoxic of the congeners (Table 1). Differences were observed with regard to the relative sensitivity of the donor 1 and 2 hepatocytes in that hepatocytes of donor 2 were approximately one order of magnitude less sensitive to MCLR -RR and OA (Table 1; Figs. $7 \mathrm{~A}$ and $\mathrm{B}$ ). Indeed exposure to the cell-permeant $\mathrm{OA}$ yielded $\mathrm{EC}_{50}$ values of $3.0 \mathrm{nM}\left(2.4-3.8 \mathrm{nM} ; \mathrm{R}^{2}=0.9698\right)$ and $35.1 \mathrm{nM}(24.5-$ $50.2 \mathrm{nM} ; R^{2}=0.8394$ ) in donors 1 and 2 , respectively.

Similar to the observations made with HEK293-OATP transfectants, no protective effect of TC was found in primary human hepatocytes of donor 3 when co-exposed to 5 MM MCLR (Fig. 8A). TC itself proved to be cytotoxic to primary hepatocytes at concentrations $\geq 166.7 \mu \mathrm{M}$. Moreover, BSP at concentrations $\geq 33.3 \mu \mathrm{M}$ was cytotoxic to primary human hepatocytes (Fig. 8B). However, despite the 


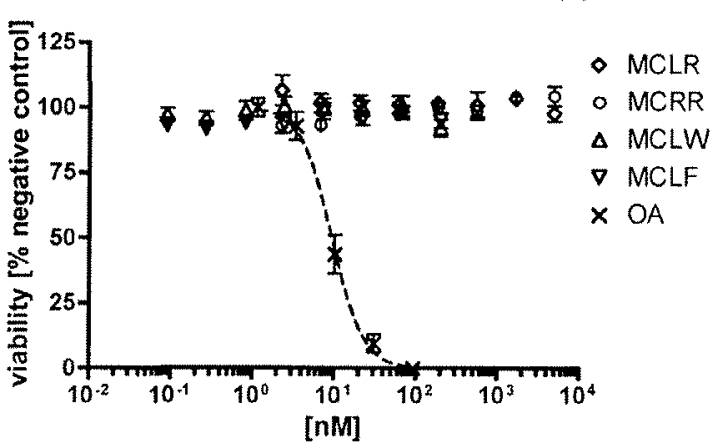

B

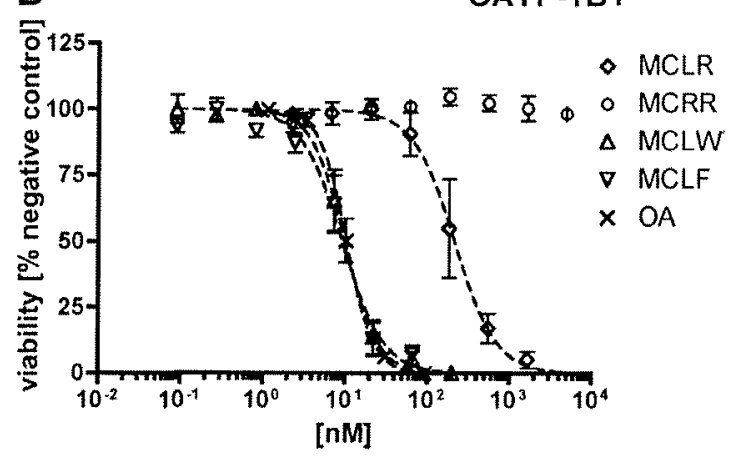

C

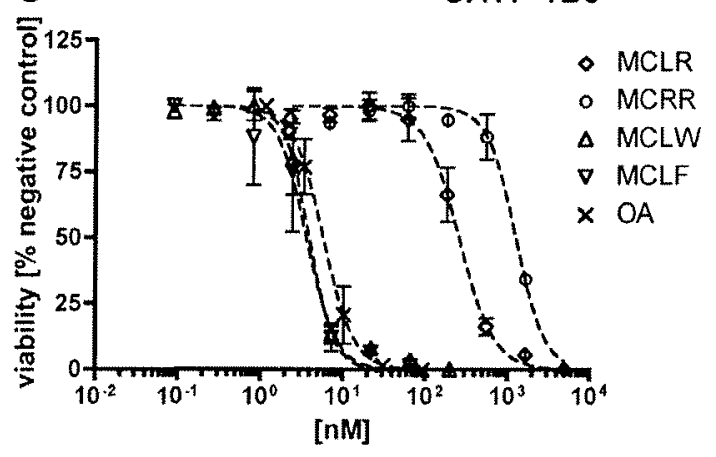

Fig. 5. Cytotoxicity of MCLR, -RR, -LW, -LF and OA in HEK293-CV (A). HEK293-OATP1B1 (B) and HEK293-OATP1B3 (C). Negative control = medium control. Values represent mean $\downarrow$ standard error of the mean of $\geq 3$ independent experiments.

observed BSP inherent cytotoxicity, BSP afforded some protection against $5 \mu \mathrm{M}$ MCLR-induced toxicity, albeit only at $100 \mu \mathrm{M}$ BSP.

\section{Discussion}

Both human primary hepatocytes and OATP-transfected HEK293 cells provided for decisive advantages over the more routinely employed HepG2 or Mz-Hep-1 cells. Indeed, within the first 96 h of seeding human primary hepatocytes retain most if not all transporters (Jigorel et al., 2005) and drug metabolizing enzymes at levels comparable with those in situ (reviewed in Li, 2001; Gomez-Lechon et al. 2003; Donato et al. 2008). Hence, results obtained from human primary cells are of greater physiological relevance than those obtained from imnortal or immortalized cell lines. Despite the latter, differences among donors 1-3 (age, genetic differences, health and dietary history etc.) can provide for data variability. In view of the latter, the same gender and comparable age groups of the donors, with the exception of donor 4 who belonged to an older age group, were employed for the experiments presented here.
In contrast, the advantage of using OATP expressing cell models, e.g. the OATP-transfected HEK293 cells, is the reproducibility and limited variability of results obtained as well as the absence of other possibly interfering transporters, thereby guaranteeing causality of transporter associated effects. Indeed, Keppler et al. (Keppler, 2006; personal communication) tested HEK293 cells for the presence of several membrane transporters. Neither background of endogenous OATP1B1 and OATP1B3 or of other endogenous OATPs was detected. Consequently, the comparison of primary human hepatocytes with HEK293 cells expressing functional hepatic OATPs would allow understanding of the potential differences in MC congener-mediated apical cytotoxicity. However, one of the prerequisites for such a comparison is that MC congeners are comparable in their capability of inhibiting endogenous ser/thr-PPs. Consequently, apical cytotoxicity was solely a resultant of the amount of PP inhibiting MC being transported within the experimental exposure time-frame. Comparable PP inhibiting capability of the four $\mathrm{MC}$ congeners tested was indeed demonstrated for recombinant PP1 and PP2A (Table 1; Fig. 1) and for homogenates of all HEK293 cells (Fig. 2), thus corroborating earlier findings by Robillot and Hennion (2004), Hoeger et al. (2007) and, with the exception of MCRR, by Monks et al. (2007).

A limited supply of primary human hepatosytes from one and the same donor prevented a comparable MC congener comparison as carried out with the HEK293 OATP transfectants. However, a PP inhibition assay with a mixture of homogenates of donors 1 and 2 and $M C$ and $O A$ demonstrated PP inhibition albeit at much lower levels than observed in the HEK293 cells (Fig. 2F), possibly suggesting lower amounts of ser/thr-PPs in the primary human hepatocytes. Indeed, MCs and OA maximally reduced total PP activity by approximately $25-35 \%$ and $15 \%$, respectively (Figs. 2A-E) in HEK293 cells. In contrast, MC-LR and OA led to a maximum reduction of total PP activity of 10-15\% in the primary human hepatocytes tested (Fig. 2F). Given that MCs and OA are specific inhibitors of distinct ser/thr-specific PPs, whereas the employed p-nitrophenyl phosphate ( $\mathrm{pNPP}$ ) is substrate for all PPs, these results would suggest that the ratios of ser/thr-PPs to total PP activity were different in the HEK293 and the primary human hepatocytes employed. The latter interpretation is supported by the fact that:

1) Total PP activity of primary human hepatocytes determined by the colorimetric protein phospluatase inhibition assays (CPPIAs) was comparatively low, since 7.5 times more total protein was needed to get a similar pNPP turnover as in the HEK293 cells, suggesting decreased PP activities.

2) Immunoblot detection of PP1 and especially PP2A in both cell types revealed distinctly weaker bands for primary hepatocytes of donor 4 (Fig. 3) and of the donor 1 and 2 mixture (see Fig. 1S). although equal protein amounts were employed.

3) Densitometric analyses using PP to GAPDH ratios, suggested that PP1 and PP2A levels in primary human hepatocytes of donor 4 were only $35 \%$ and $8 \%$, respectively, of the levels found in HEK 293 transfectants (see Table 15).

Although the latter may also be due to differences in the protein phosphatase-epitopes in HEK293 cells and primary hepatocytes, thereby altering primary antibody epitope recognition and binding specificities (Michalski et al., 2002; Letschert et al, 2004; Lee et al. 2005), the principle finding of the cPPIAs strongly supports the finding that MC congeners have comparable PP inhibiting capacities in human cell lines (HEK293) as well as in primary human hepatocytes of donors 1 and 2 . Thus differences in apical cytotoxicity observed among MC congeners or among cell lines or cell types appear to be primarily driven by the type and expression levels of OATPs, albeit differences in protein phosphatase type and expression levels cannot be ignored.

Since the HEK293 were originally transfected by subcloning the OATP CDNAs into the expression vector pCDNA3.1 (+) (König et al., 
$2000 \mathrm{a}, 2000 \mathrm{~b})$, thus being under control of the same promoter (cytomegally virus), it may be assumed that the HEK 293 cells were stably expressing comparable levels of recombinant human OATP1B1/SLCO1B1 and OATP1B3/SLCO1B8. The latter assumption was at least qualitatively supported by the immunofluorescence staining for the two OATP transporters (Fig. 4), thus allowing the assumption that any apical MC congener-induced cytotoxicity is not

A

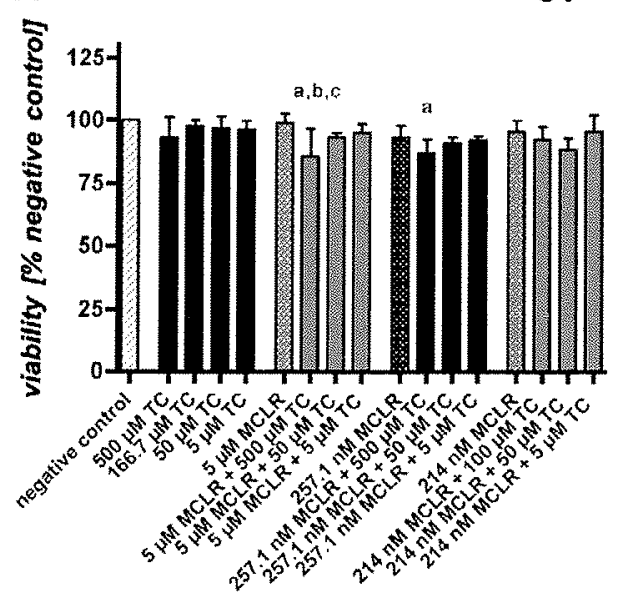

C

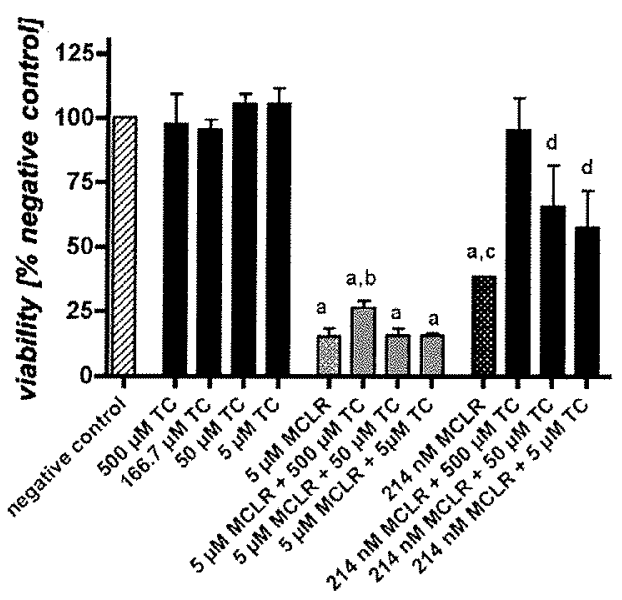

E

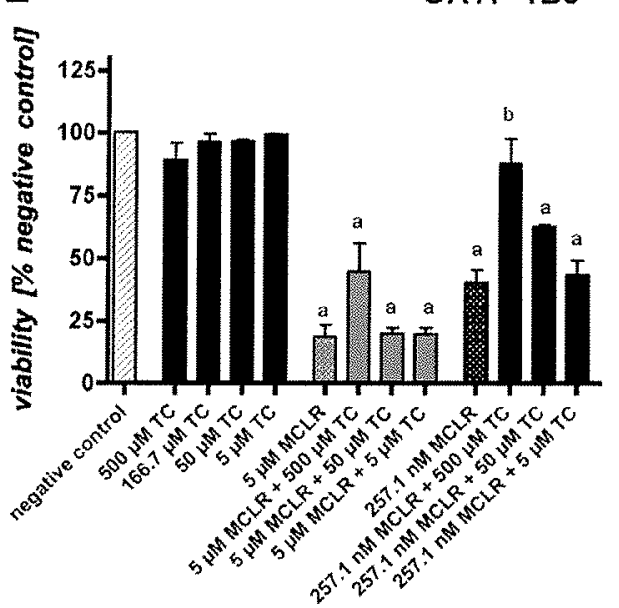

the result of differences in PP and / or OATP expression among the two HEK293 transfectants. Indeed, the levels of PP expression following densitometric analyses appeared to be comparable among all HEK293 transfectants (Table 1S). MC cytotoxicity was congener-dependent (Table 1; Fig. 5) in both OATP-expressing HEK293 cells. Since no differences in intracellular PP inhibition among $\mathrm{MC}$ congeners were observed, it can be assumed that cytotoxicity directly reflects varying
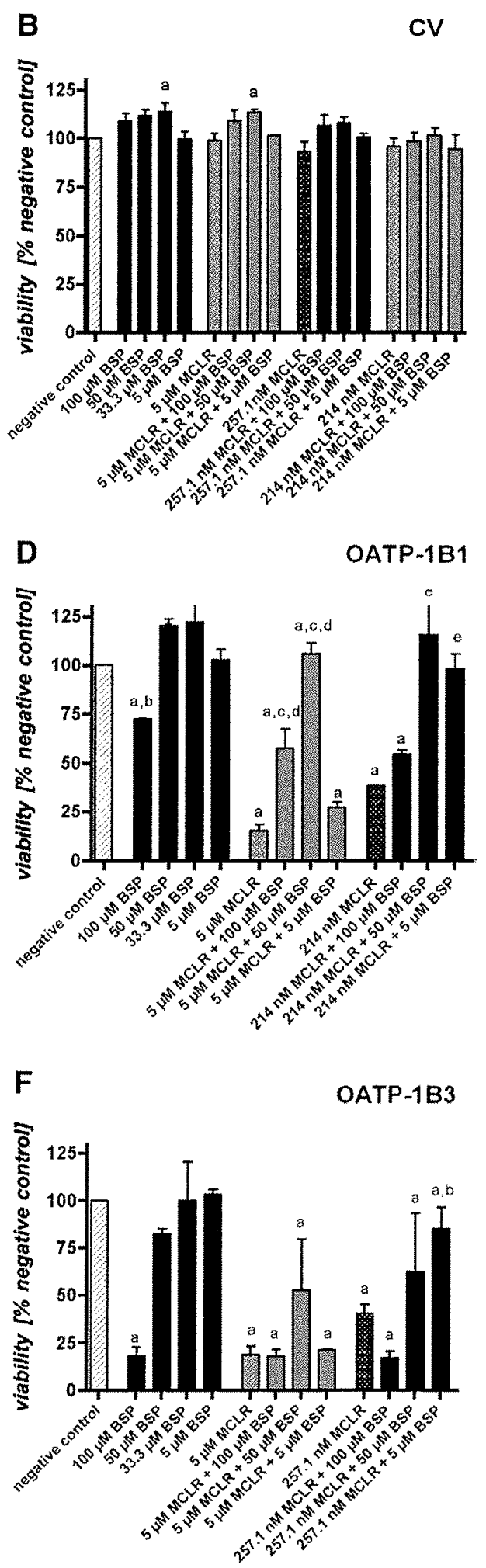

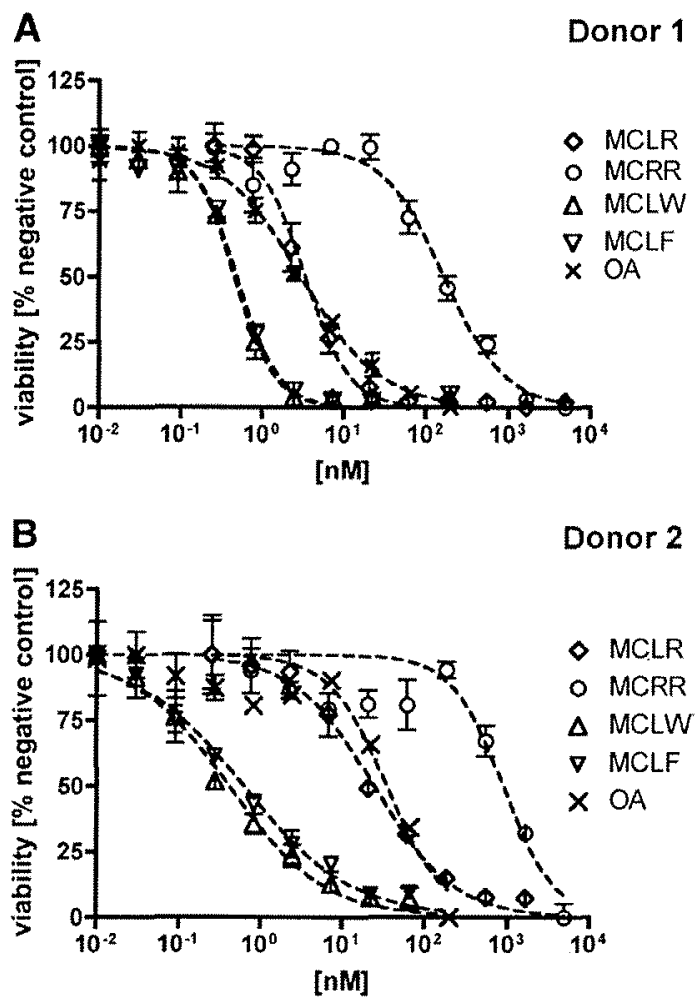

Fig. 7. Cytotoxicity of MCLR, $-R R,-L W,-L F$ and $O A$ in primary human hepatocyces of donors $1(A)$ and donor 2 (B). Negative control =medium control. Values represent mean \pm standard error of the mean $\geq 3$ independent experiments.

affinities and transporting capacities of the OATP expressed for the respective MCs. The more hydrophobic MC congeners $\mathrm{LW}$ and $\mathrm{LF}$ elicited the highest effects with similar $48 \mathrm{~h} \mathrm{EC}_{50}$ values each in the low nanomolar range. Remarkably, MCLR appeared to be approximately 20 times and 60 times less toxic than MCLW and -LF in OATP1B1- and OATP1B3-expressing HEK293 cells, respectively. MCRR was the least cytotoxic congener and elicited no effects in HEK293OATP1B1 at all concentrations applied. HEK293-OATP1B3 were more than 300 times less susceptible to MCRR than to MCLW and MCLF. No cytotoxicity was observed in control vector-transfected HEK 293 cells. thus confirming the assumed OATP transport-dependent uptake with ensuing cytotoxicity for all four MC congeners.

The latter findings confirmed the general trend observed in earlier cytotoxicity data in Hela cells transiently transfected with OATP1B1 and OATPJB3 (Monks et al., 2007), albeit the 72 h EC 50 s obtained for MC-LW and -LF in the transiently transfected HeLa cells were in the subnanomolar tange. The overt differences in $\mathrm{EC}_{50}$ s obtained with the transiently transfected HeLa when compared to the stably transfected HEK293 cells reported here, most likely are a reflection of (a) different expression levels of the respective OATPS, (b) differences in PP type and expression levels, (c) duration of exposure and (d) metabolic (Phase and II) differences (Grisham et al., 1978; Hugo-Wissemann et al., 1991; Nyberg et al., 1994; Stange et al., 1995; Donato et al., 2008).
A

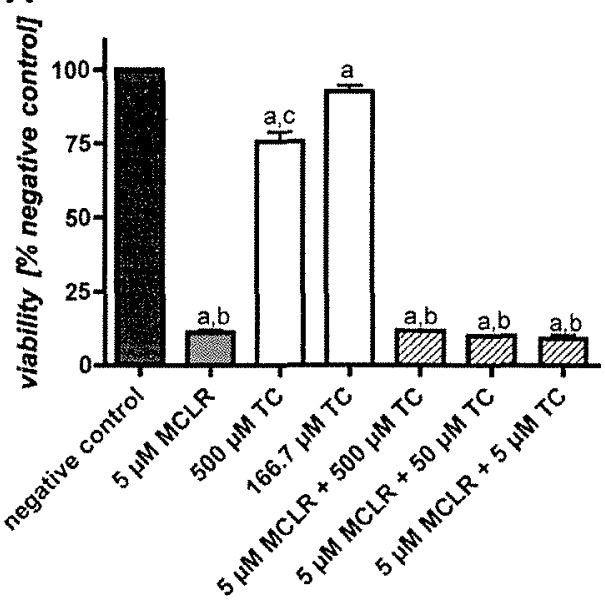

B

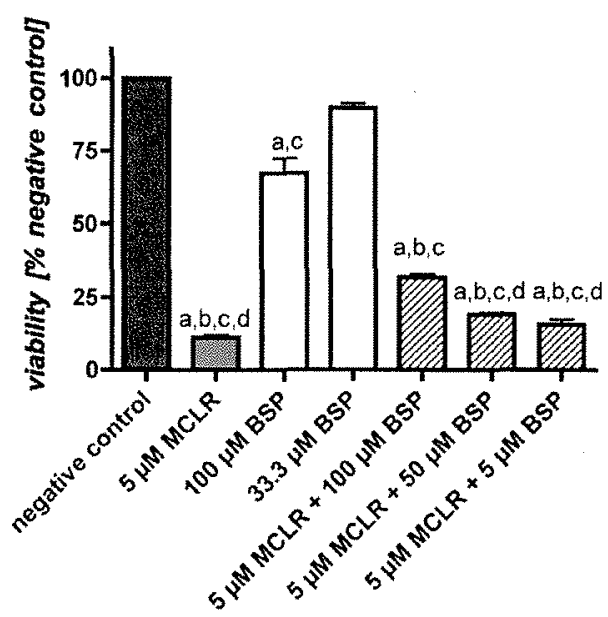

Fig. 8. Competitive inhibition of MCLR uptake in primary human he patocytes of donor following co-incubation with $\mathrm{TC}$ ( $A$ ) and BSP (B). Negative control = medium control Values represent mean \pm standard error of the mean of four independent experiments. Statistics: One-way ANOVA followed by Tikey's Multiple Comparison Test was employed to assess significant differentes between all groups (controls and exposures with/without TC or BSP). (A) a: significantly different $(p<0.05)$ from the negative control, b: significantly different $(p<0.001)$ from the 500 and $166,7 \mathrm{H}$ T TC group $c$ : significantly different $(p<0.05)$ from $166,7 \mu \mathrm{N}$ TC-only group: (B) a: significanty different $(p<0.001)$ from the negative control; b: significantly different $(p<0.001)$ from the 100 HM BSP group, c: significantly different $(p<0.001)$ from the $33.3 \mathrm{HM}$ BSP group d: significantly different ( $p<0.004$ ) from 5 LM MCLR + $100 \mu \mathrm{M} \mathrm{BSP}$ group

Most importantly, the finding of transport affinity-dependent MC toxicity was confirmed by the results obtained from exposure of primary human hepatocytes to single MC congeners (Fig. 7). The primary hepatocytes of donors 1 and 2 demonstrated a higher susceptibility toward the more hydrophobic MC congeners: MCLW and MCLF appeared to be about 7 to 60 times and 7 to 39 times more toxic than the corresponding MCLR, respectively, whereas a roughly

Fig. 6. Competitive inhibition of MCLR uptake in HEK293-CV (A, B), HEK293-OATP1B1 (C, D) and HEK293-OATP1B3 (E, F) following Co-incubation with TC and BSP. Negative control = medium control Valies represent mean standard error of the mean of $\leq 7$ independent experinents. Statistics: One-way ANOVA followed by Tukey's Multiple Comparison Test was employed to assess significant differences berween all groups (controls and exposures with/without TC or BSP). (A) a: significantly different ( $p<0.001$ ) from

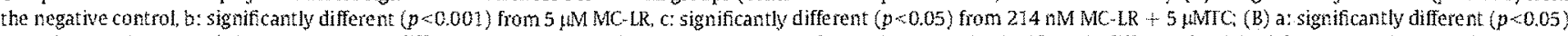
from the negative control: $(C)$ a significantly different $(p<0.05$ ) from the negative control and TC-only groups, $b$ : significantly different ( $p<0.001)$ from 5 um $M C-L R$, $c$ significantly different $(p<0.001)$ from all $214 \mathrm{nM} \mathrm{MC-LR}+$ TC groups, d: significantly different $(\beta<0.01)$ from the negative control and the 50 and $5 \mu \mathrm{M}$ TC-only groups; (D) a: significantly different $(p<0.01)$ from the negative control and BSP only groups, b: significantly different $(p<0.05)$ from 50 , 33, and 5 uM BSP-only groups, $c$ significantly different $(p<0.001)$ from

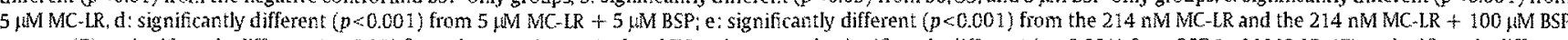
groups; ( $E$ ) a: significantly different $(p<0.05)$ from the negative control and TC-only groups, b: significantly different $(p<0.00 \mathrm{~L})$ from $257.1 \mathrm{nM} M C-L R$. ( $F$ ) a: significanty different $(p<0.05$ ) from the negative control and BSP-only groups, b: significantly different $(p<0.01)$ from the $257.1 \mathrm{nM} M C-\mathrm{LR}+100 \mathrm{MM}$ BSP. 
37 to 49 times lower susceptibility toward MCRR than to MCIR was observed.

In general, primary human hepatocytes of donors 1 and 2 appeared to be up to two orders of magnitude more susceptible to MC-induced cytotoxicity than the corresponding HEK293 OATP transfectants (Table 1). Moreover, vast differences in MCLR and -RR cytotoxicity were observed among the two donors tested. While the former could stem from a difference in metabolic capability between HEK293 cells and primary human hepatocytes as well as among donors (donors 1-3) of the primary hepatocytes, the latter could result from a difference in OATP expression level as well as other factors among the donors of the primary hepatocytes, despite that care was taken to ensure that all donors were female and that donors 1-3 were from the same age group. Some of these factors, beyond age and gender, are condition and metabolic capability of the respective donor's hepatocytes, i.e largely dependent on the donor's constitution, disease history, or to metabolic alteration during culturing (Bissell et al., 1978; Castell and GomezLechon, 2009). Metabolic conversion, eg. glutathione conjugation of MC, renders the MC-GSH conjugate much less toxic (Kondo et al, 1992). Hence, cells with lower levels of GSH-transferase or depleted of GSH will be more susceptible to MC-induced PP inhibition and thus cytotoxicity. However, given that above interpretation holds true, it would remain to be proven that the GSH conjugation of MC congeners $L R$, RR, LW and LF is congener dependent.

The expression levels of OATPs in primary human hepatocytes appear to vary within different zones of the liver. König et al. (König et al., 2000b) reported stronger OATP1B3-immunofluorescence staining near the central vein than close to the portal vein suggesting a lobular zoning of OATP expression. Hence, the differences in MC congener susceptibility in the primary human hepatocytes observed among donors in this study could also be a reflection of differences in hepatic zonal origin introduced during liver biopsy of donors 1 and 2 .

The direct proof of OATP-mediated uptake of MCs via use of radiolabeled substrates was not possible due to the unavailability of radiolabeled MCs. As an alternative, co-incubation studies with the known OATP substrates TC and BSP, as competitor of MCLR, were employed. These uptake competition studies should provide for indirect evidence of MC uptake into HEK293 transfectants (Fig. 6) and primary human hepatocytes of donor 3 (Fig. 8), and thus support the findings of the cytotoxicity studies. Protection against MCLR-mediated cytotoxicity by co-incubation with TC and BSP could be observed in HEK293OATPIBI and -OATP1B3, hence, providing further evidence for OATPmediated uptake of MCs. None of the applied concentrations of TC provided for protection against 5 MM MCLR neither in primary human hepatocytes nor in OATP-transfected HEK293 cells. In contrast, BSP appeared to afford some protection from MCLR-mediated cytotoxicity in primary human hepatocytes (100 $\mu \mathrm{M}$ BSP) and in HEK293-OATP1B1 (100 $\mu \mathrm{M}$ and $50 \mu \mathrm{M}$ BSP). Notably, the lack and limited protection afforded by TC and BSP, respectively, in primary human hepatocytes (Fig. 8) may be explained by the fact that the primary human hepatocytes have very low levels of ser/thr PPs (Fig. 3) whereby already minute concentrations of MCLR entering the primary hepatocytes will suffice to induce cytotoxicity. The latter is also confirmed by the results of the cytotoxicity experiments (Fig. 7; Table 1) demonstrating the higher susceptibility of primary human hepatocytes to MC toxicity than the corresponding HEK293 transfectants (Fig. 5; Table 1) containing higher quantities of ser/thr PPs (Fig. 3).

Generally increased protection against MCLR cytotoxicity was observed in HEK293 OATP-transfectants when co-incubating TC and BSP with lower concentrations of MCLR. Indeed, the higher the concentration of TC, the higher the cytoprotective effect toward MCLR cytotoxicity. In contrast, 5 HM BSP provided highest protection against MCLR in HEK293-OATP1B3 cells, while concentrations $\geq 50 \mu \mathrm{M}$ BSP appeared to be cytotoxic as well. HEK293-OATPIB1 cells were less susceptible to BSP cytotoxicity, BSP thus affording a much higher protective effect toward MCLR cytotoxicity (Fig. 6).
The observed reduced MC-mediated cytotoxicity upon co-incubation MCLR, -LW and -LF with TC and BSP confirms earlier findings by Feurstein et al (2009) in primary murine whole brain cells, known to express mOatp1b2, of the OATP1B family (including rat roatp $1 \mathrm{~b} 2$, human OATP1B1 and OATP1B3; Hagenbuch and Meier, 2004).

As the ser/thr-specific protein phosphatase inhibitory capacity of the four different MC congeners were comparable in vitro (comparable toxicodynamics, Table 1), the observed overt differences in MC congener apical toxicity in vivo (i.p. $\mathrm{LD}_{50}$ values) had been at the center of discussion for the last two decades. Certainly, a possible central role of toxicokinetics and thus the superfamily of OATPs has been assumed by Fischer et al. (2005), Dietrich and Hoeger (2005), Dietrich et al. (2008) and Komatsu et al. (2007). However, supporting scientific evidence has so far remained scarce. The cytotoxicity results presented in this study using HEK293 OATP-transfectants (Fig. 5), as well as primary human hepatocytes (Fig. 7) thus emphasize the importance of toxicokinetics for understanding of the factors underlying the observed $i n$ vivo differences in toxicity among various $\mathrm{MC}$ congeners. Indeed, the $48 \mathrm{~h} \mathrm{EC}$ 50 value for MCRR using OATP1B3transfected HEK293 cells was approximately 5-fold higher than MCLR, whereas OATP1B1-transfected cells were resistant to MCRR cytotoxicity. In primary human hepatocytes, the viability $\mathrm{EC}_{50}$ values for MCLR and MCRR differed by a factor of 35 to 50 depending on the donor (1 or 2). Distinct differences between MCLR and -RR toxicity have also been reported from other in vitro studies: Fastner et al. (1995) and Eriksson et al. (1990) demonstrated that primary rat hepatocytes are less susceptible to MCRR $\left(\mathrm{EC}_{50} 1500-4300 \mathrm{nM}\right.$ ) than to MCLR (EC $60-200 \mathrm{nM}$ ).

Thus, irrespective of the cells used (primary hepatocytes or transfected HEK293). MCRR was always 1-2 orders of magnitude less cytotoxic than MCLR. This difference in cytotoxicity compares well with the approximately 1 -order of magnitude difference (i.p. $\mathrm{LD}_{50}$ values) observed in acute mouse in vivo toxicity between MCRR and MCLR (Krishnamurthy et al., 1986; Watanabe et al., 1988; Lovell et al., 1989; Stoner et al., 1989).

\section{Conclusion and possible implication for present risk assessments}

The results derived from the OATP-transfected HEK293 cells and the primary human hepatocytes presented here provide strong evidence that the more hydrophobic MCLW and -LF are distinctly more toxic than MCLR in vitro and thus potentially also in vivo. The higher toxicity of MCLF and -LW was also reported for primary murine whole brain cells (Feturstein et al., 2009) and for the protozoa Tetrahymena pyriformis (Ward and Codd, 1999). Given that all in vitro experiments with MCRR and -IR provided a similar toxicity ratio as the mouse in vivo i.p. $\mathrm{LD}_{50}$ assays (Table 1 ), one can assume that an in vivo mouse i.p. exposure to MCLF and -LW would also provide for a higher toxicity of MCLF and -LW than what is reported for MCLR and -RR. As all present microcystin risk assessments and evolving guidelines values are based on data derived from in vivo exposures to MCLR, a more in-depth analysis of the risk posed by other MC congeners, e.g. MCLF and $-\mathrm{IW}$, may be warranted.

Moreover, the distribution and abundance of MCLW and $-\mathrm{LF}$ in environmental samples have to be taken into consideration with regard to their importance for risk assessments. Unfortunately, only little information exists on their occurrence in natural samples like bloom material. Azevedo et al. (1994) made the first report on MCLF isolated from a bloom of $M$ aeruginosa from a Brazilian water supply. Spoof et al. (2003) investigated 93 samples from freshwater and brackish water locations in Finland, whereby 34 samples contained concentrations of MC or nodularin $\geq 0.2 \mu \mathrm{g} / \mathrm{l}$. However, only in one sample MCIF and traces of MCLW were detected. Interestingly, an earlier analysis of two natural bloom samples of $M$ aeruginosa in Scotland, and the rumen contents from a lamb that died after ingestion of scum from one of those samples, revealed a similar MC 
profile (including MCLW and -LF) as the strain $M$ aeruginosa PCC 7813 (Lawton et al., 1995) in which MCLW and -LF have repeatedly been detected (Lawton et al., 1995; Ward and Codd, 1999; Metcalf and Codd, 2000). The authors therefore consider a much more widespread occurrence of MCLW and -LF variants than previously assumed. Thus, MCLW and -LF might pose an unknown, yet serious threat to human and animal health

In conclusion, OATP-dependent cytotoxicity underlines the importance of identifying and characterizing further peptides responsible for the cell trafficking of different MC congeners using both transfected cell line models and primary cells. It must be assumed that more OATPS and most likely other membrane carriers are capable to transport MC into and out of various cell types of organisms. Indeed, to date only 4 out of 11 known human OATPs have been tested for uptake of MC, namely OATP1 A2, -1B1, -1B3 and -2B1 (this study; Fischer et al., 2005; Komatsu et al.. 2007; Monks et al., 2007). Since only OATP2B1 failed in transporting MC, it appears very likely that some untested OATPS are capable of microcystin transport. Knowledge of MC congener-specific transport is crucial for the understanding of MC toxicity, induding organ distribution, and hence, the improvement of human risk assessments and establishment of guideline values.

\section{Acknowledgments}

We would like to acknowledge the Arthur \& Aenne Feindt Foundation (Hamburg, Germany), the BMBF (01G60732-AKN), as well as the European Union (PEPCY OLRT-2001-02634) for kindly funding parts of this study. We would also like to thank Prof. Dr. Dietrich Keppler (Division of Tumor Biochemistry, German Cancer Research Centre, Heidelberg, Germany) for kindly providing the transfected HEK293 cells, Dr. Elisa May, Christine Strasser and Daniela Hermann (Bio Imaging Centre, University of Konstanz, Germany) for the introduction and assistance to laser confocal microscopy, as well as Alicja Panas, Jasmin Leyhausen, Julia Kleinteich and Isabelle Eisele for practical assistance.

\section{Appendix A. Supplementary data}

Supplementary data associated with this article can be found, in the online version, at doi:10.1016/j,tap.2010.02.006.

\section{References}

Azevedo, S.M.F.O. Evans, W.R., Carmichael. W.W., Nanikoshi, M., 1994. First report of microcystins from a Brazilian isolate of the cyanobacterium Microcystis aeruginosa J. Appl. Psychol. 6, 261-265.

Batista. T., de Sousa, G., Suput, IS. Rahmani, R., Stuput, D., 2003. Microcystin-LR causes the collapse of actin filaments in primary human hepatocytes. Aquat. Toxicol. 65 $85-91$

Bissell, D.M., levine, G.A. Bissell, M.J., 1978. Glucose metabolism by adult hepatocytes in primary culture and by cell lines from ra liver Am. I. Physiol. $234, \mathrm{C} 122-\mathrm{C} 130$

Botes, D.P., Tuinman, A.A., Wessels, P.L, Viljoen, C.C, Kruger, H. Williams, D.H. Santikam, S. Snith. R.J. Hammond, S.J. 1984. The structure of cyanoginosin-LA, a cyclic heptapeptide toxin from the cyanobacterium Microcystis aeruginosa. I. Chem cyclic heptapeptide toxin from the

Botes, D.P., Wessels, P.L, Kruger, H., Runnegar, M.T.C, Santikarn, S., Smith, R.J., Barna, I.C. Williams, D.H, 1985 . Structural studies on cyanoginosins $-L R,-Y R,-Y A$, and $-Y M$ peptide toxins from Microcystis aeruginosa l. Chem, Snc. Perkin Trans. 1, 2747-2748.

Bradford, M.M., 1976. A rapid and sensirive merhod for the quantification of mirogram guantities of protein utilizing the principle of protein-dye binding. Anal. Biochem. $72,248-254$.

Carmichael, W.W., Beasley, V., Bunner, D.L, Eloff, J, N. Falconex, l., Gorham, P., Harada, K. Krishnamurthy, T., Yit, M.., Moore, RE, et al., 1988 . Naming of cyclic heptapeptide toxins of cyanobacteria (blue green algae). Toxicon $25,971-973$.

Castell, IV. Gomez-Lechon, M. J, 2009. Liver cell culture techniques. Methods Mol. Biot $481,35-46$.

Dietrich, D. Hoeger, S, 2005. Cuttdance values for microcystios in water and cyanobacterial supplentent products (blue-green algal supplements): a reasonable or misguided approach? Toxicol. Appl. Pharmacol. 203, 273-289.

Dietrich, D.R., Fischer, A., Michel, C, Hoeger, S.I., 2008. Toxin mixture in cyanobacterial blooms-a critical comparison of reality with current procedures employed in human health risk assessment. Adv. Exp. Med. Biol. 619. 885-9i2.
Donato, M.T., Lahoz, A. Castell, J.V., Gomez-Lechon, M.J., 2008. Cell lines: a tool for in vitro drug metabolism studies. Curr. Drug Metab. 9. 1-11.

Eriksson, J.E., Gronberg, L, Nygard, S., Slotte, J.P., Merilwoto, J.A., 1990a. Hepatocellular uptake of $3 \mathrm{H}$-dihydromicrocystin-LR, a cyclic peptide toxin. Biochim. Biophys. Acta $1025,60-66$.

Eriksson, JE., Toivola, D. Meriluoto, J.A., Karaki. H. Han, Y.G., Hartshorne, D., 1990 Hepatocyte defomation induced by cyanobacterial toxins refects inhibition of protein phosphatases. Biochem. Biophys. Res. Commun. 173, 1347-1353.

Fastner, J. Heinze, $R$, Chorus, I., 1995. Microcystin-content, hepatotoxicity and cytotoxicity of cyanobacteria in some German water bodies. Water Sci. Tech. 32 $165-170$.

Feurstein, D., Holst, K., Fischer, A, Dietrich, D.R., 2009. Oatp-associated uptake and toxicity of microcystins in primary murine whole brain cells. Toxicol. App Phamacol. 234, 247-255.

Fischer W. Al theimer, S. Cattori, V. Meter. P.J., Dietrich, D.K., Hagenbuch, B. 2005 Organic anion transporting polypeptudes expressed in liver and brain mediate uptake of microcystin. Toxicol. Appl. Pharmacol. 203, 257 263.

Gomez-Lechon, M.]., Donato, M.T., Gastell, J.V., Jover, R., 2003. Hunan hepatocyes as a tool for studying toxicity and drug metabolism. Curr. Drug Metab. 4, 292-312.

Grisham, JW. Chatton, KK, Kaufman, D.G., 1978. In vitro assay of cytotoxicity with cultured iver: accomplishments and possibilities. Environ. Health Perspect. 25. $161-171$

Hagenbuch, B., Meier, P.J. 2003. The superfamily of organic amion transporting polypepides. Biochim. Biophys. Acta 1609, 1-18.

Hagenbuch, B.. Meier. P.J., 2004. Organic anion transporting polypeptides of the DATP/SLC21 family: phylogenetic classification as OATP/ SLCO superfamily new nomenclature and molecular/functional properties. Plugers Arch. 447 $653-665$.

Harada, K., Matsuura, K., Suzuki, M., Watanabe, M.F., Oishi, S., Dahlen, A.M., Beasley, V.R. Camichael, WW. 1950. Isolation and characterization of the minor components associated with microcystins LR and RR in the cyanobacterim blue-green algae Toxicon $28,55-64$

Hastie, C. . Borthwick, E.B. Morrison, L.F. Codd, G.A., Cohen, P.T., 2005. Inhibition of several protein phosphatases by a non-covalently interacting microcystin and a novel cyanobacterial peptide, nostocyclin. Biochim. Biophys. Acta 1726, 187-193.

Heresztyn, I. Nicholson, B.C, 2001 . Determination of cyanobacterial hepatotoxins directly in water using a protein phosphatase inhibition assay. Water Res. 35 , $3049-3056$

Hoeger, S.I. Schmid, D., Blom, J.F., Ernst, B., Dietrich, D.R. 2007. Analytical and functional characterization of microcystins [Asp3]MC-RR and [Asp3,Dhb7]MC-RR: consequences for risk assessment? Environ. Sci. Technol. 41, 2609-2616.

Honkanen, RE Codispoti B A Tse, K Boynton, A L Honkanan, R F, 1994 Characterization of natural toxins with inhibitory activity against serine/ threonine protein phosphatases. Toxicon 32, 339-350.

Hugo-Wissemann, D., Anundi, I. Lauchart, W. Viebahn, R., de Groot, H., 1991 Differences in glycolytic capacity and hypoxia tolerance between hepatorna cells and hepatocytes. Hepatology 13, 297-303.

Humpage, A, 2008. Toxin types, toxicokinetics and toxicodynamics. Adv. Exp. Med Binl. $619,383-415$.

Jigorel, E, Le Vee, M., Boursier-Neyret, C., Bertrand, M., Fardel, 0 , 2005. Functional expression of sinusoidal drug transporters in primary human and rat hepatocytes. Drug Merab. Dispos. 33, 1418-1422.

Komatsu, M., Furukawa, T., Keda, R., Takumi, S., Nong, Q. Aoyama, K. Akiyama, S, Keppler, D., Takeuchi, T., 2007. Involvement of mitngen-activated protein kinase signaling pathways in microcystin-LR-induced apoptosis after its selective uptake mediated by OATP1B: and OATP1B3. Toxicol. Sci. 97, 407-416.

Kondo, F, lkai, Y., Oka, F., Okumura, M., Ishikawa, N., Harada, K., Matsuura, K., Murata H. Suzukj. M., 1992. Formation, characterization, and toxicity of the glutathione and cysteine conjugates of toxic heptapeptide microcystins. Chem. Res. Toxicol 5 $591-596$.

König, J., Cui, Y. Nies, AT, Keppler, D., 2000a. A novel human organic anion transporting polypeptide localized to the basolateral hepatocyte membrane. Am. J. Physiot. Gastrointest. Liver Physiol. 278, G156-G164.

König. ., Cui, Y.. Nies, A.T., Keppler, D. 2000b. Localization and genoraic organization of a new heparocellular organic anion transporting polypeptide. J. Biol. Chem. 275 $23161-23168$.

Krishnamurthy, T Carmichael, WW. Saver, E.W. 1986. Toxit peptides from freshwarer chanobacteria (blue-green algae). 1. Isolation, purification and characterization of peptides from Microcystis aerugitosa and Anabaena fos-aquae. Toxicon $24,865-873$

Lawton, L.A., Edwards, C, Beattie, K.A., Pleasance. S., Dear, G.., Codd, G.A., 1995 Isolation and characterization of microcystins from laboratory culures and environmental samples of Microcystis aeruginosa and from an associated animal toxicosis. Nat. Toxins 3, 50-57.

lawton, L.A., Edwards, C, Codd, G.A, 1994. Extraction and high performance liquid chromatographic method for the determination of microcystins in raw and treated waters. Analyst $19,1525-1530$

leg, W., Gheser, H., Smith, L.H, Roberts, R.L., Moeckel, G.W., Gervasini, G. Leake, B.F Kim, K.B. 2005. Polymorghisms in human organic anion-transporing polypeptide $1 A 2$ (OATP1A2): implications for altered drug disposition and central nervous system drug entry. J. Biol Chen. 280, 9610 9617.

Letschert, K., Keppler, D., Konig, J., 2004. Mutations in the SLCO1B3 gene affecting the substrate specificity of the hepatocellular aptake transporter OATP1B3 (OATPS) Pharmacogenetics $14,441 \cdots 452$.

Li, A.P., 2001. Screening for human ADME/Tox drug properties in drug discovery. Drug Discov. Today 6, 357-366. 
Lovell, R.A. Schaeffer, D. Hooser, S.B., Haschek, W.M., Dahlen, A.M. CarmichaeL, W.W. Beastey, V.R. 1989. Toxicity of intraperitoneal doses of microcystin-LR in two strains of male mice. ]. Environ. Pathol. Toxicol. Oncol. 9, 221-237.

Lu, H., Choudhuri, S., Ogura, K., Csanaky, LL., Lei, X, Cheng, X, Song, P.Z, Klaassen, CD. 2008. Characterization of organic amion transporting polypeptide 1b2-null mice: essential role in hepatic uptake/toxicity of phalloidin and micncystin-LR. Toxicol Sci. $203,35-45$.

Mackintosh, C, 1993. Assay and purification of protein (serine/threonine) phosphazases. In: Hardie, D.G. (Ed.), Protein Phosphorylation: A Practical Approach, Oxford University Press, oxford, pp. 197-22,9.

Mejer, P.J., Stieger, B., 2002. Bile salt transporters. Annu. Rev. Physiol, 64, 635-661.

Meriluoto, J. Spoof, L., 2005. SOP: Preparation of standard solutions of microcystin-IR for HPLC calibration. In: Meriluoto, J., Codd. G.A (Eds.) TOXIC: Cyanobacterial Monitoring and Cyanotoxin Analysis, Abo Akademi Universiry Press, Abo, pp.65-67.

Meriluoto, J, Karlsson, K., Spoof, L, 2004. High-throughput screening of ten microcystin and nodularins, cyanobacterial peptide hepatotoxins, by reverse-phase liquid chromatography-electrospry ionisation mass spectrometry. Chromatographia 59 $291-298$.

Metcalf, J.S., Codd. G.A. 2000. Microwave oven and boiling waterbath extraction of hepatotoxins from cyanobacterial cells. FEMS Microbiol. Lett. 184, 241-246.

Michalski, C, Cui, Y., Nies, AT., Nuessler, A.K., Neuhats, P., Zanger, U.M., Klein, K. Eichelbaum, M., Keppler, D., Konig, I. 2002. A naturally occurring mutation in the SLC2IA6 gene causing impaired membrane localization of the hepatocyte uptake transporter. I. Biol. Chen. 277, 43058-43063.

Mikkaichi, T, Suzuki, T., Tanemoto. M.. Ito, S., Abe, T, 2004. The organic anion uansporter (OATP) farnily. Drug Metab. Phamacokinet. 19, 171-179.

Monks, N.R., Liu, S., Xu. Y., Yu, H. Bendelow, A.S., Moscow, J.A. 2007. Potent cytotexicity of the phosphatase inhibitor microcystin LR and microcystin analogues in OATP1B1- and OATP1B3-expressing Hela cells. Mol. Cancer Ther. 6, 587-598.

Nussler, A.K. Nussier, N.C. Merk, V., Brulport, M., Schormann, W., Yao, P. Hengstler. J.G. 2009. The holy grail of hepatocyte culturing and therapeutic use. In: Santin, $M$ (Ed.), Strategies in Regenerative Medicine. Springer New York, Universiy of Brighton, pp. 283-320.

Nyberg, S.L., Remmel, R.P., Mam, H.J, Peshwa, M.V., Hu, W.S., Cera, E.B., 2994 . Primary hepatocytes outperform Hep $G 2$ cells as the source of biotransformation function in a bioartificial liver. Ann. Surg. 220,59-67.

Ohta, T., Nishiwaki, R., Yatsunami, I. Komori, A., Suganuma, M., Fujiki, H., 1992 Hyperphosphorylation of cysokeratins 8 and 18 by microcystin-LR, a new liver tumor promoter, in primary cultured rat hepatocytes. Carcinogenesis 13 tumor promo $2443-2447$.

Price, P.]. 1975. Preparation and use of rat-tail collagen. Me hods Cell Sci. 1, 43-44.

Rinehart, K.L, Harada, K.-I., Namikashi, M., Chen, C. Harvis, C.A. Munro, M.H.G., Blunt, J.W Multigan, P.E., Beasley, B.R., Dahlen, A.M., Carmichael, W.W. 1988. Nodularir microcystin, and the configuration of adda. J. Am. Chem. Soc. 110, 8557-8558.

Rinehart, K.L., Namikoshi, M., Choi, B.W., 1994. Structure and biosynthesis of toxirs from blue-green algae (cyanobacteria). I. Appl. Psychol. 6, 159-176.
Rotillo:, C., Hernion, M.C. 2004. Issues arising when interpreting the results of the protein phosphatase $2 \mathrm{~A}$ inhibition assay for the monitoring of nicrocystins. Anal. Chim. Acta $5 \llbracket 2,339346$.

Rumnegar, M. Berndt, N., Kaplowitz, N., 1995a. Microcystir uptake and inhibition of protein phosphatases. effects of chemoprotectants and self-intibition in relation to known hepatic transporters. Toxicol. Appl. Pharmacol. 134, 264-272.

Runnegar, M.. Bemdt, N., Kong, S.M., Lee, E.Y., Zhang, L., 1995. In vivo and in vitro binding of microcystin to protein phosphatases 1 and $2 \mathrm{~A}$. Biochem. Biophys. Res Commun. 216, 162-169.

Sivonen, K. Jones, $G_{\text {. }} 1999$. Cyanobacterial toxins. In: Chorus, l., Bartram, ]. (Eds.), Toxic Cyanobacteria in Water: A Guide to their Ptolic Health Consequences, Monitoring and Maragement. E \& FN Spon, London, pp. 41-111.

Spoof, L., 2005. Microcystins and nodularins. In: Merilıoto, J., Codd. G.A. (Eds.), In Toxic: Cyanobacterial Monitoring and Cyanotoxin Analysis. Abo Akadem Universiny Press, pp. 15-39.

Spoof, L, Vesterkvist, P., Lindholm, T., Meriluoto, J, 2003. Screening for cyanobacterial hepatotoxins, microcystins and nodularin in environmental water samples by reversed-phase liquid chromatography-electrospray ionisation mass spectrometry. I. Chromatog: A 1020, 105-119.

Stange, J. Mitzner. S., Strauss, M. Fischer, U. Lindemann, S. Peters, E., Holtz, M Drewelow, B., Schmid, R., 1995. Primary or established liver cells for a hybrid liver? Comparison of metabolic features. ASAJO I. 41, M310 M315.

Stoner, R.D., Adams, W.H., Slatkin. D.N., Siegelman, I.W, 1989. The effects of single t-amino acid substitutions on the lethal potencies of the nicrocystins. Toxican 27, 825-828.

Toivola, D.M., Goldman, R.D. Garrod, D.R., Eriksson, J.E., 1997. Protein phosphatases mainain the organization and structural interactions of hepatic keratin inter mediate filaments. J. Cell. Sci. 110, 23-33.

van Montfoor, J.E., Hagenbuch, B., Groothuis, G.M., Koepsell, H. Meier, PJ, Meijer, D.K 2003. Drug iptake systems in liver and kidney. Curr. Drug Metab. 4, 185-211.

Ward, CJ.. Codd, G.A, 1999. Comparative toxicity of four microcystins of different bydrophobicities to the protozoan, Tetrahyment pyriformis. J. Appl. Microbiol. 86 $874 m 882$.

Watanabe, M.F, Oishi, S., Harda, K, Matsuura, K., Kawai, H., Suzuki, M., 1988. Tokin contained in Microcystis species of cyanobacteria (blue-green algae). Toxicon 26 $1017-1025$.

Wickstrom, M.L., Khan, S.A., Haschek, W.M., Wyman, JF., Eriksson, J.E, Schaeffer, D.J. Beasley, V.R. 1995. Alterations in microtubules, intermediate filaments, and microfilaments induced by microcystin-LR in cultured cells. Toxicol. Pathol. 23. 326-337.

Yoshizawa, S., Matsushima, R., Watanabe, M.F, Harada, K. Ichihara, A., Carmichael, W.W. Fujiki, H., 1990. Inhibition of protein phosphatases by microcystins and nodularin associated with hepatotoxicity. J. Cancer Res. Clin. Oncol. 116, 609-614.

Zurawell, R.W. Chen, H., Burke, IM., Prepas, E.E. 2005. Hepatotoxic cyanobacteria: review of the biological importance of microcystins in freshwater environments. J. Toxicol. Environ. Health B Cril Rev, 8, 1-37. 